\title{
Adherence Syndrome
}

National Cancer Institute

\section{Source}

National Cancer Institute. Adherence Syndrome. NCI Thesaurus. Code C35811.

A disorder which limits movement of the eye following ocular surgery. It is caused by the inadvertent scarring down of the middle portion of the inferior oblique muscle at or near the insertion of the inferior rectus muscle. Clinical signs include hypotropia and excyclotropia. Surgical release of the incarcerated segment will usually correct the deviation of the affected eye. 